\title{
Multifund choices within a lifecycle investment model The Colombian Case
}

\author{
Camilo Andrés Gómez Morales \\ Economic Environment Research Group \\ Universidad EAN \\ Cam_Gome@hotmail.com
}

\author{
Nelson A. Andrade-Valbuena. \\ Economic Environment Research Group \\ Universidad EAN \\ nandrade4923@ean.edu.co
}

\author{
Fabio Fernando Moscoso Durán \\ Chief Economic Environment Research Group \\ Universidad de EAN \\ ffmoscoso@ean.edu.co
}

\begin{abstract}
The purpose of this research is to study the welfare impact on consumption that lifecycle investors constrained to make compulsory contributions into a pension fund will get by choosing a multifund. The use of simulation techniques is applied to a life cycle investment model designed to fit the situation of the Colombian private pension system. It shows the importance of combining the percentage of investments in equity in the pension fund with the structure of human capital in
\end{abstract}


order to determine which investment vehicle individuals should be chosen in order to save for retirement.

Keywords: Multifunds; Lifecycle Investment Model; Colombia; Human Capital Structure.

JEL classification: G11; G17; G23.

\section{Resumen}

Este trabajo busca describir y analizar la evolución de la disciplina de la Gestión de Recursos Humanos en su proceso de génesis, desarrollo, cambios e institucionalización en la actual Facultad de Economía y Negocios de la Universidad de Chile desde una perspectiva de una narrativa histórica-heurística en el período comprendido entre 1958 y 1973.

Palabaras clave: Multifondos; modelo de inversión del ciclo de vida; Colombia; estructura de capital humano.

\section{Introduction}

Before 1993 the Colombian pension system was organized as a Pay as You Go scheme run by the government, the system is known as the Average Pension Regime (APR) and it behaves as a Defined Benefit (DB) Plan where an individual regularly contributes part of his salary into the system and in return he/she will receive with certainty every month a percentage of the average of the salaries he/she received during the last ten years of working life ${ }^{1}$.

In 1993 the system mentioned above was starting to show the following problems ${ }^{2}$ :

${ }^{1}$ In 2015 as long as a male has contributed to the RPM system for 25 years he will get $65 \%$ of his 10 year average salary.

${ }^{2}$ Fedesarrollo "Pension system in Colombia: Challenges and alternatives to increase coverage", April 2010. 
- Unequality

- Low Coverage

- Financial unsustainability

According to Venegas (1996), only $21.5 \%$ of the population in Colombia was covered by the social security system while in other Latin American countries this ratio was in the order of $61.2 \%$, and out the people that earned minimum wage only $16.7 \%$ was covered while the $66.1 \%$ of the higher income population was covered making the system highly unequal, on top of that the government argued to the congress in order to reform the pension system that the fiscal deficit caused by the then actual pension system was in the order of $73 \%$ of GDP by 1990 , with no probability of falling down without meaningful reforms.

In order to overcome the above problems, in 1993 a new system that would coexist with the (APR) was introduced by the Government. This system is called the Individual Savings with Solidarity Regime (ISSR), and it behaves as a Defined Contribution (DC) Plan, in which the individual contributes part of his salary every month which will be invested by a Pension Fund Administrator (PFA).

Until 2010 the portfolio allocation of the retirement savings of 10 million Colombian workers were managed at the discretion of PFA's following the guidelines of the Government. In this compulsory DC system with fixed contributions the individual's retirement income will depend on the asset returns generated over the investment horizon and the contributions paid to the pension system. In a DB plan retirements benefits also depend on the contributions paid by the individual but the financial risk is the responsibility of the sponsor of the pension fund.

For the reasons exposed above in a DC plan individuals are the bearers of the financial risk and it may be reasonable to allow these agents who may have different characteristics, to choose from different investment alternatives. 
In this regard the government of Colombia published Decree $\mathrm{N}^{\mathrm{o}} 2373^{3}$ whose purpose is to give pension participants the choice to adopt different investment strategies among three multifunds offered by Pension Fund Administrators (PFA) while restricting these individuals to adopt aggressive stock allocations when they are close to retirement.

The multifund system started in January of 2011, however by April of that year, only $0.2 \%$ of contributors made an active choice to enrol in a multifund this experience is in line with countries like Mexico and Chile, although much more pronounced ${ }^{4}$. In the case of Colombia if individuals don't make a decision then by default they will be enrolled in the moderate multifund whose characteristics will be explained further along this document.

Since it is important for participants in a pension fund to understand the importance of choosing the right alternative for retirement savings and assuming that financial literacy is not the main strength of the average individual ${ }^{5}$. The purpose of this research is to study the welfare impact on consumption that lifecycle investors constrained to make compulsory contributions into a pension fund will get by choosing a multifund.

The motivation behind this study is to increase the available body of academic knowledge that financial practitioners can have at their disposal in order to give meaningful recommendations to individuals in the important decision of saving for retirement in the most efficient way.

${ }^{3}$ On July 12010 this decree establishes the multifunds system for managing the mandatory pension resources of the Individual Solidarity Savings System (RAIS) and programmed retirement pensions based on law 1328 of 2009.

4 Anif "Daily commentary" February 14 2012. In Chile 17\% of participants enrolled when the system started.

${ }^{5}$ Mitchell, O. and S. Utkus (2003), Lessons from Behavioral Finance for Retirement Plan Design, Pension Research Council Working Paper 2003-6, University of Pennsylvania. 
The document is organized in six sections, section 2 reviews the literature of the life cycle investment theory. The third section will be a description of the model for multifunds. Section four is dedicated to a description of the parameters in our model. Section five is a discussion of the model through simulations and finally, the sixth section concludes.

\section{Literature}

A. The case for constant allocation into risky assets over the lifecycle

One of the most cited reasons used by financial practitioners to argue for age varying investment strategies, such as the one proposed by multifunds is that young people should have a high allocation into risky assets because over long time horizons, the probability of a shortfall declines with the length of the investment horizon. This proposition is rejected by Merton (1969) and Samuelson (1969) using counterarguments based on expected utility maximization and by Bodie (1995) using option pricing theory.

In fact it is shown in related papers by Merton (1969) and Samuelson (1969) that the stock allocation for lifecycle investors must be constant and independent of the time horizon:

$$
W=\left[\frac{\bar{\mu}-r_{f}}{\gamma * \sigma^{2}}\right]
$$

Where:

$w=$ allocation to risky asset

$\bar{\mu}-r_{f}=$ expected excess return

$\gamma=$ risk aversion

$\sigma^{2}=$ variance of the risk assets return. 
The assumptions behind the model are the following:

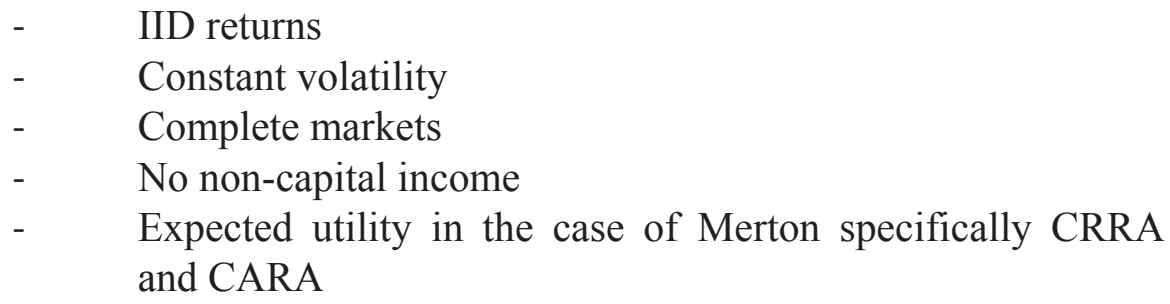

Since Merton uses Tobin's Theorem ${ }^{6}$, the remainder of the portfolio for a lifecycle investor should be invested into riskless assets. If the allocation into risky assets is constant over the lifecycle, then the optimal consumption for the individual depends on the financial results that this investment provides.

The model mentioned above predicts a constant asset allocation during the lifecycle, however if the assumptions behind the model change then we get scientific arguments in favour of a decreasing asset allocation into risky assets over the lifecycle.

\section{B. The importance of Human Capital on portfolio choice}

On the side of labour income and lifecycle portfolio allocation we can find examples in Bodie et al. (1992), Heaton and Lucas (1997), Cocco et al. (2005) and Benzoni et al. (2007). The main conclusion on this research is that the value, riskiness, and flexibility of a person's labor earnings are very important when deciding on portfolio allocations at each stage of the life cycle.

One of the most important papers to mention the role of human capital in portfolio choice is Cocco et al. (2005), which is an

${ }^{6}$ Tobin's theorem says that the optimal portfolio can be found combining cash and a portfolio of risky assets which makes investors with different degrees of risk aversion indifferent. 
empirically calibrated model that deals with incomplete markets and finds optimal consumption and asset allocation decisions in a realistic setting. The main conclusion of the model is that ignoring human capital in portfolio decisions implies huge costs in terms of welfare for individuals.

In order to reach the above conclusion Cocco et al. (2005) calibrate the income profiles for United States workers using data from the Panel Study of Income Dynamics (PSID). They make the assumption that the expected excess return of risky assets will be $4 \%$ constant and they employ a dynamic optimization technique in order to find optimal consumption and investment decisions at each point in time using backward induction.

Although this model is highly sophisticated, it is possible to approximate some conclusions by simulating income profiles and stock returns, while using closed form formulas for investment and consumption decisions employing simulation methods.

It is important to find income profiles using real data or by simulation methods since the product of labour from an individual can be transformed in income and it can supposed that the repeated process of working for labour income can and must be approximated as a form of wealth.

This wealth can be measured as the sum of the present value of the cash flows from future labour income discounted at a given discount rate.

$$
H C_{t}=\sum_{j=t}^{n} \frac{Y_{j}}{1+\rho}
$$


Where:

$H C_{t}$ is human capital,

$Y_{j}$ is income in future period $j$, and

$\rho$ is the discount rate.

Total wealth then must be the sum of financial wealth $F_{t}$ and human capital $H C_{t}$ :

$$
W_{t}=F_{t}+H C_{t} \text {. }
$$

And in the special case when labour income is riskless human capital will be considered as a financial position in a riskless asset. Resulting in an optimal portfolio weight for stocks that will be given by De Jong et al. (2008) as:

$$
\pi_{t}^{*}=\frac{\bar{\mu}-r_{f}}{\gamma^{*} \sigma^{2}} * \frac{1}{1-h}=\frac{\bar{\mu}-r_{f}}{\gamma * \sigma^{2}} * \frac{W_{t}}{F_{t}}
$$

For $F_{t}>0$,

Where

$$
h=\frac{H C_{t}}{W_{t}}
$$

For young investors the value of human capital will be very large compared to financial capital, implying large portfolio weights in risky assets. For example in Teulings et al. (2006) it is estimated that a young individual should invest 5.50 times his first year labour income into risky assets. This is a very compelling argument for the case that young individuals should have a very high allocation into stocks, without having to mention the lower risk for stocks in long horizons which is a case that is still open.

Another enhancement to the theory could be to consider the possibility that labour income is not riskless. For example De Jong 
(2008) finds that there is a regression coefficient $\beta_{H}$ that measures the exposure between stock returns and human capital returns based on quarterly data from the United States and the Netherlands in the order of 0.18 . This regression coefficient can be found by the following formula:

$$
\beta_{H}=\frac{\operatorname{cov}\left(R_{S}, R_{H}\right)}{\sigma^{2}}
$$

Where

$R_{S}$ are stock returns and

$R_{H}$ can be for example labour growth rates expressing human capital returns.

When $\beta_{H}$ is different than zero then the formula for the allocation into stocks using De Jong (2008) is: (see appendix 1)

$$
\pi_{t}^{*}=\left[\frac{\bar{\mu}-r_{f}}{\gamma^{*} \sigma^{2}}-h * \beta_{H}\right] * \frac{1}{1-h} .
$$

In this case the optimal allocation into stocks is hedged in part by the correlation between human capital and stock returns, meaning that with a higher correlation the demand for stocks falls. De Jong (2008) also makes it clear that the optimal allocation given by the expression above is only exact if markets are complete and labour income doesn't have any idiosyncratic risk, in other cases portfolio allocations into stocks will be smaller than what the formula suggests.

\section{Relaxing the other assumptions}

The academic interest in exploring the effects on lifecycle asset allocation when the assumptions in Merton's model are relaxed as in the case of the review found above when human capital exists can 
be found. For example on the side of investment opportunities in Brennan and Xia (2002), Campbell and Viceira (1999) and Koijen et al. (2011) who consider riskless interest rates that are not constant. Also Campbell and Viceira (1999) and Wachter (1998) consider changes in the equity premium.

In classical lifecycle investment models such as the ones mentioned above, there are not compulsory rules that oblige individuals to save for retirement. One adaptation to resemble a world where individuals are obligated by the government to save for retirement can be found in Campbell et al. (1999).

In Campbell's model, individuals have stochastic income, with a deterministic working life but uncertain lifespan. These agents are obligated to save for retirement in a special account managed by the government. In this retirement account the allocation into the risky asset is fixed and after retirement individuals receive a riskless annuity. During working life after the contribution to the retirement wealth account is made, individuals make investment and consumption decisions with their disposable income and the liquid wealth they have accumulated. There are only to assets to choose from, a risky and a risk free asset. Individuals cannot borrow to finance consumption and short sales are not allowed. In order to invest in risky assets outside the retirement system individuals have to pay a fixed cost of entry to the stock market. This assumption is made because it is argued in that model that young and poor individuals don't invest in stocks. At retirement individuals will receive $60 \%$ of last year working salary in every period.

The main conclusions of Campbell's model is that allowing for some portion of retirement social security savings into risky assets can increase the welfare of individuals, however they also find that this gains vary according to personal characteristics of individuals such as risk preferences and discount factors. 


\section{Model Setup}

A. Using existing literature to develop a multifund lifecycle model

As a point of reference to develop a model in a framework of multifunds in Colombia, we will adapt Campbell's lifecycle model by introducing some changes to make the model simpler and other changes in order to resemble the realities that individuals face when they contribute to the Colombian mandatory private pension system. In the model for this research individuals have a deterministic lifespan. They don't have to pay a fixed cost to invest in the stock market with their liquid wealth. At the time of retirement, the wealth accumulated in the compulsory system will be paid in periodic instalments. After each payment, the available retirement wealth will be invested in the risk free asset until the account is depleted at the time of death. The asset allocation in the retirement account during working life will be variable according to the investment rules that will be explained in subsection 3.G.

We will focus on the presence of human capital as a determinant for the saving and investment decisions individuals could make inside and outside the retirement system, in order to increase their welfare. The outcomes from the simulations are then compared to reach points of reference to make more educated decisions when individuals have to choose an investment vehicle for retirement purposes.

\section{B. $\quad$ Time parameters and preferences}

Let $t$ denote the age of an adult individual, who lives until the age $T$, out of which he works for $K$ periods and then retires for $L$ periods, for this model $K$ and $L$ are assumed certain, deterministic and exogenous . 
The utility preferences of this individual are described by a constant relative risk aversion utility function as:

$$
E\left[\sum_{t=1}^{T} \delta^{t-1} \frac{C_{t}^{1-\gamma}}{1-\gamma}\right]
$$

Where:

$C_{t}$ consumption at date is $t$.

$\gamma$ is the coefficient of relative risk aversion and is the subjective personal discount factor.

\section{Labour income process}

An individual's labour income when he/she starts to work equals a sum $Y_{1}$ which is exogenous, after the first period the individual's income will be given by the following equation adopting Gourinchas and Parker (2002):

$$
\begin{aligned}
& Y_{t}=P_{t} U_{t} \\
& P_{t}=G_{t} P_{t-1} N_{t}
\end{aligned}
$$

Where the $\log$ of permanent income $\ln P_{t}$ evolves as a random walk with age specific drift in $\ln G_{t}$. The permanent shock of income is independent and log-normally distributed $\ln N_{t} \sim N\left(0, \sigma_{N}^{2}\right)$, and the temporary income shock is also independent and log-normally distributed $\ln U_{t} \sim N\left(0, \sigma_{u}^{2}\right)$. 
The equations will be applied in logarithmic form as:

$$
\begin{aligned}
& \ln (Y)_{t}=\ln \left(P_{t}\right)+\ln \left(U_{t}\right) \\
& \ln \left(\frac{P_{t}}{P_{t-1}}\right)=\ln \left(G_{t}\right)+\ln \left(N_{t}\right) .
\end{aligned}
$$

\section{Financial assets}

It is assumed that the individual can only invest in two assets, a riskless asset $B$ with return $r_{f}$, and a risky asset $S$, with $\log (S)$ evolving as a random walk that follows a geometric Brownian motion:

$$
S_{t+1}=S_{t} * \exp ^{\left(\left(\mu_{S}-\frac{\sigma_{S}^{2}}{2}\right)+\sigma_{S} \theta_{t+1}\right)} .
$$

Where

$\mu_{S}$ and $\sigma_{S}$ are the mean and standard deviation of the risky asset, and $\theta_{\mathrm{t}}$ is a stochastic shock distributed as $N(0,1)$.

In logarithmic form the evolution of the risky asset is the following:

$$
\ln \left(\frac{S_{t+1}}{S_{t}}\right)=\left(\mu_{s}-\frac{\sigma_{S}^{2}}{2}\right)+\sigma_{s} \theta_{t+1} .
$$

\section{E. Retirement and liquid wealth}

Since saving for retirement is a compulsory part of the pension system. During working life the individual receives the following disposable income: 


$$
Y_{t}^{d}=Y_{t} *(1-\phi)
$$

Where

$\phi$ represents the fraction of income that the individual must save with the pension fund. This fraction is exogenous and is not necessarily optimal.

The retirement savings allocated to the pension fund constitute the individual's retirement wealth $W^{R}$, it is not possible to consume this retirement wealth during working life. When the individual no longer works, retirement wealth will be invested in a risk free asset and spread into a series of periodic payments for the remaining lifetime. Outside of this compulsory system the individual can also save. This savings will constitute liquid wealth $W^{L}$.

\section{F. Human Capital}

Human capital is given by:

$$
H C_{t}=\sum_{j=t}^{n} Y_{j} *(\exp (t-j) * \rho)
$$

Where

$\rho=r f$ if there is not correlation between human capital returns and stock returns and if the correlation exists then:

$$
\rho=r f+\beta_{H} *\left(\bar{\mu}-r_{f}\right) \text {; and } \beta_{H}=\frac{\operatorname{cov}\left(U_{t}, \theta_{t}\right)}{\sigma_{\theta_{t}}} \text {. }
$$




\section{G. Saving process and consumption decisions}

\section{a. SAVING PROCESS}

The saving process evolves as follows:

In every period the individual starts with a certain amount of liquid wealth $W^{L}$, retirement wealth $W^{R}$, and labour income $Y_{t}$ is realized.

During the lifetime period the available individual's liquid resources can be expressed using Deaton (1991) as cash on hand:

$$
\operatorname{Cash}_{t}=\left(\left(\Delta \ln \left(S_{t}\right)-r_{f}\right) * \pi_{t}^{*}+r_{f}\right) * W_{t}^{L}+Y_{t}^{d}
$$

Where the allocation to the risky asset will be given by: (see appendix 2).

$$
\pi_{t}^{*}=\left[\frac{\bar{\mu}-r_{f}}{\gamma * \sigma^{2}}-\frac{W_{t}^{R}}{W_{t}} * \beta_{R}-\frac{H C_{t}}{W_{t}} * \beta_{H}\right] * \frac{W_{t}}{W_{t}^{L}} .
$$

Where

$W_{t}=W^{L}+W^{R}+H C_{t}$

And $\beta_{R}$ is the asset allocation in the risky asset invested in the multifund. As explained in subsection 2.B when there is correlation between human capital returns and stock returns, this effect will reduce the demand for stocks, the same can be said when there are compulsory savings for retirement, in this case the allocation into stocks for liquid wealth will be determined also by the amount of stocks already allocated in the retirement account, the higher the allocation in the multifund, individuals will have a reduced allocation into stocks with their liquid wealth. 


\section{b. CONSUMPTION DECISIONS}

With the cash on hand the investor will consume and using Merton (1969) the amount of consumption will be given by the following equation:

$$
C_{t}^{*}=\left[\frac{v}{1-e^{v *(t-T)}}\right] * W_{t} .
$$

Where

$$
v=\frac{\rho}{\gamma}+\left(1-\frac{1}{\gamma}\right)\left(\frac{r_{f}+0.5 * \varphi^{2}}{\gamma}\right)
$$

And $\rho$ is the discount factor and $\varphi=\frac{\mu-r_{f}}{\sigma}$.

In this model it is not possible for the individual to borrow money to fund current consumption, and short positions in financial assets are not allowed.

$$
\begin{aligned}
& S_{t} \geq 0 \\
& B_{t} \geq 0 \\
& W_{t} \geq 0 \\
& C_{t}=\min \left(C_{t}^{*}, \text { Cash }_{t}\right)
\end{aligned}
$$

These borrowing constraints ensure that the investor will have a maximum consumption of his income plus the amount of liquid wealth at his disposal in every period, at the same time the short sale constraints guarantee that the individual can't have leveraged positions into financial assets.

Since the consumption equation stated above ignores the possibility of future borrowing constraints; it is not optimal, but it 
may be a relative good approximation of the optimal choice of consumption.

\section{H. The process of investing in the multifund system}

Although the multifund system allows the presence of multiple investment assets, the model is abstracted in the following way, since in our model only two assets are present:

From age 22 until 57, the participant can choose only one out of the three multifunds offered. In reality, the participant can change his choice every six months but the intention of the simulation is to find which model offers the greatest welfare for a participant age 22 . We consider this abstraction does not invalidate the conclusions of this research.

The multifunds offered are in the table 1 .

Table 1

Multifunds offered in Colombia

\begin{tabular}{|l|c|c|}
\hline & \% RISKY ASSET & \% RISKLESS ASSET \\
\hline Conservative & 20 & 80 \\
\hline Moderate & 45 & 55 \\
\hline Aggressive & 70 & 30 \\
\hline
\end{tabular}

And the weight allocations will be fixed although in reality PFA's can change the allocation into the risky asset along some guidelines given by the government are in the table 2 . 


\section{Table 2}

Allocation of risky asset

\begin{tabular}{|l|c|c|}
\hline & MINIMUM \% & MAXIMUM \% \\
\hline Conservative & 0 & 20 \\
\hline Moderate & 20 & 45 \\
\hline Aggressive & 45 & 70 \\
\hline
\end{tabular}

The government also establishes a mandatory convergence rule which in the case of an individual male age 57 can be describe as follows (table 3).

Table 3

Mandatory convergence rule for a 57 years old male

\begin{tabular}{|c|c|}
\hline AGE & \% INVESTED IN CONSERVATIVE FUND \\
\hline 57 & 20 \\
\hline 58 & 40 \\
\hline 59 & 60 \\
\hline 60 & 80 \\
\hline 61 & 100 \\
\hline
\end{tabular}

The Table 3 shows that for an individual that is invested in the aggressive fund, the PFA will change his allocation into $20 \%$ for the conservative fund and $80 \%$ in the aggressive fund at age 57 , and when he reaches the age of 62 all the money for retirement will be invested in the conservative fund (see Figure 1). 


\section{Figure 1}

Asset allocation: Risky asset aggressive multifund (70\%)

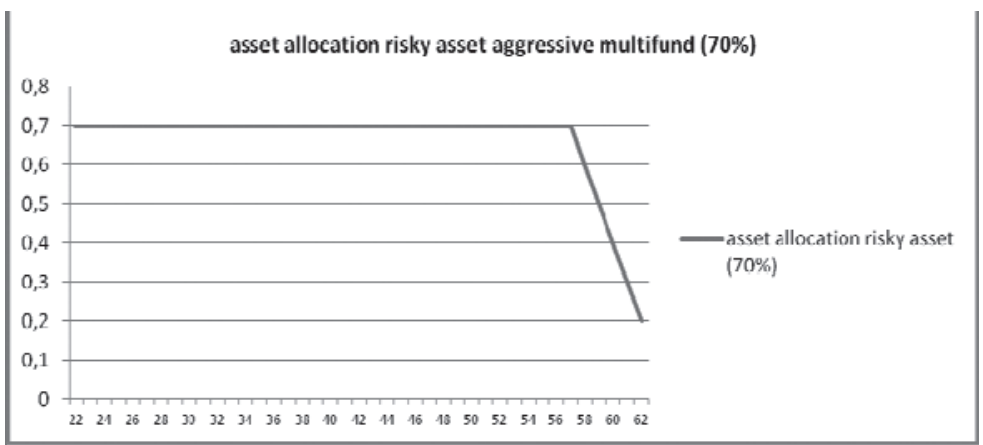

\section{Parameters and Methodology}

A. $\quad$ Time parameters and preferences

Adult age starts at age 22. The age of retirement is set at 62 in accordance with Colombia's retirement age for male workers, and the retirement period is set for simplicity at 23 years. The discount rate of preference is set to $4 \%$, which is the average between the preference used in Bodie et al. (1992) and Teuling and Devries (2006). Different levels of risk aversion and different degrees of correlation between human capital and financial asset returns will be considered in order to give a proper welfare analysis.

B. Expected rates of financial returns.

The real average equity return $\mu$ is set at $8.62 \%$, this calculation is the result of the following: The historical average annualized log real return in local currency generated by the Colombian Market equity index (IGBC) from august 2001 until December 2011 is 
$17.42 \%{ }^{7}$. At the same time government regulations allow pension funds in Colombia to invest abroad. The allowed allocation into foreign investments before the transition to multifunds for Pension Fund Administrators was $40 \%$ of total investments, and of this amount according to new regulations the amount that has to be hedged for currency exposure is $50 \%$ for the aggressive multifund ${ }^{8}$. With this information the result is that the average real rate of return for the MSCI world index ${ }^{9}$ for the same period is $-0.25 \%$ for the hedged part of the portfolio and $-8.9 \%$ for the unhedged part. The striking result for the unhedged portfolio comes from the fact that Colombia has experienced a currency appreciation of $16 \%$ against the US dollar during this period of 10 years (See figure 2).

\section{Figure 2}

Calculations are from the authors with information provided by Central Bank of Colombia

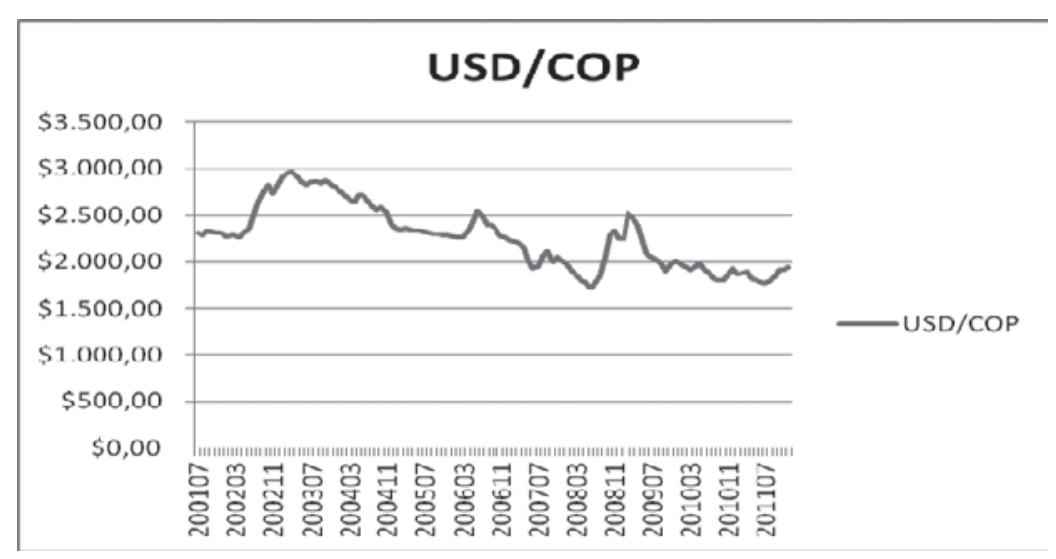

${ }^{7}$ In 2001 there was a merger between the Bogota, Medellin and Cali stock exchanges, forming the Colombia stock exchange. The result is that reliable price data is found only from that year and after. Data source: Datastream.

${ }^{8}$ Republic of Colombia, Decree 857, March 23 ${ }^{\text {rd }} 2011$, page 20.

${ }^{9}$ The MSCI World Index is a free float-adjusted market capitalization weighted index that is designed to measure the equity market performance of developed markets. Information taken from www.msci.com 
The weights, annualized standard deviation for the returns and correlations of the equity portfolio are in table 4, table 5 and table 6 .

Table 4

Weight in the portfolio of returns calculation of the equity portfolio

\begin{tabular}{|c|c|c|}
\hline \multicolumn{3}{|c|}{ Weight in the portfolio of returns calculation } \\
\hline$M S C I$ HEDGED & $M S C I$ UNHEDGED & $I G B C$ \\
\hline $20 \%$ & $20 \%$ & $60 \%$ \\
\hline
\end{tabular}

Table 5

Standard deviation of the equity portfolio

\begin{tabular}{|c|c|c|}
\hline \multicolumn{3}{|c|}{ Standard Deviation } \\
\hline MSCI HEDGED & MSCI UNHEDGED & IGBC \\
\hline $17.84 \%$ & $16.26 \%$ & $25.4 \%$ \\
\hline
\end{tabular}

Table 6

Matrix correlations of the equity portfolio

\begin{tabular}{|c|c|c|c|}
\hline \multicolumn{4}{|c|}{ Matrix of correlations } \\
\hline & MSCI & MSCI PESOS & IGBC \\
\hline MSCI & 1 & 0.83 & 0.47 \\
\hline MSCI PESOS & 0.83 & 1 & 0.34 \\
\hline IGBC & 0.47 & 0.34 & 1 \\
\hline
\end{tabular}


With this data we set the standard deviation at $18.81 \%$. Using Ito's lemma the expected return on equity will be $\bar{\mu}=\mu+\frac{\sigma^{2}}{2}$ and equal to $10.39 \%$.

The riskless real interest rate is set at $1.92 \%$, which is the average of the FTD (Fixed Term Deposits) ${ }^{10}$ for the same period used in the calculation for equity returns.

\section{Labour income process}

For the income process the model was calibrated using $1.2 \%$ as the deterministic rate of growth in labor income taken from Urrutia (2008). Cocco et al. (2005) estimated the annual standard deviation of the labor income at about $10.95 \%$ for permanent and $13.89 \%$ for temporary shocks. Though Viceira (2009) argue that half of this standard deviation is attributable to measurement error, he ends up using this data for Chile assuming higher volatility for emerging economies.

The starting annual salary will be COP\$ $17.294 .160^{11}$ and this sum is equivalent to approximately USD\$ 9.000 using the equivalent currency exchange rate between the Colombian Peso and the United States Dollar for December 2010.

${ }^{10}$ The FTD is calculated by the Colombian Securities and Banking Commission every week and is an average of the interest rate paid by banks for 90 day deposits.

${ }^{11}$ This information is taken from the "Employment Observatory National University Colombia" for a recent university graduate for the year 2010. http://www.universidad.edu.co/index.php?option=com content\&view=article\&id= 2230:salarios-lo-confirman-a-mas-estudio-y-experiencia-mejores-ingresos\&catid= 16: noticias\&Itemid $=198$ 


\section{Multifund parameters}

In all cases the contribution rate towards the compulsory retirement system will be $11.5 \%$ of annual income and this sum will be invested into the scheme outlined in section 3 .

\section{Discussion of the model}

\section{A. Baseline case}

Using the model and the parameters described above we will run 100,000 simulations of possible income and stock return paths. Then we choose a representative individual with a coefficient of risk aversion of 5 who makes no compulsory contribution to the pension fund. Our intention is to show how consumption, wealth accumulation and allocation into the risky asset behave in a setting with no government intervention and then making changes to multifund choices, introduce background risk and correlation to labour returns in order to find the highest ex-ante utility for individuals with different risk preferences.

In Figure 3 the simulation of 100,000 different paths shows the difference in final wage that can result from the labour income uncertainty described in the parameters, in Table 7 . It can be seen that the mean is around COP\$ 35,640.00 with a standard deviation of COP\$28,557.81 which is higher than the median of around COP\$ 27,920.00. These results are in line with Viceira (2009), implying a large dispersion in pension contributions even when this contributions are invested in risk free assets. 


\section{Figure 3}

Evolution of Stochastic Income (SI)

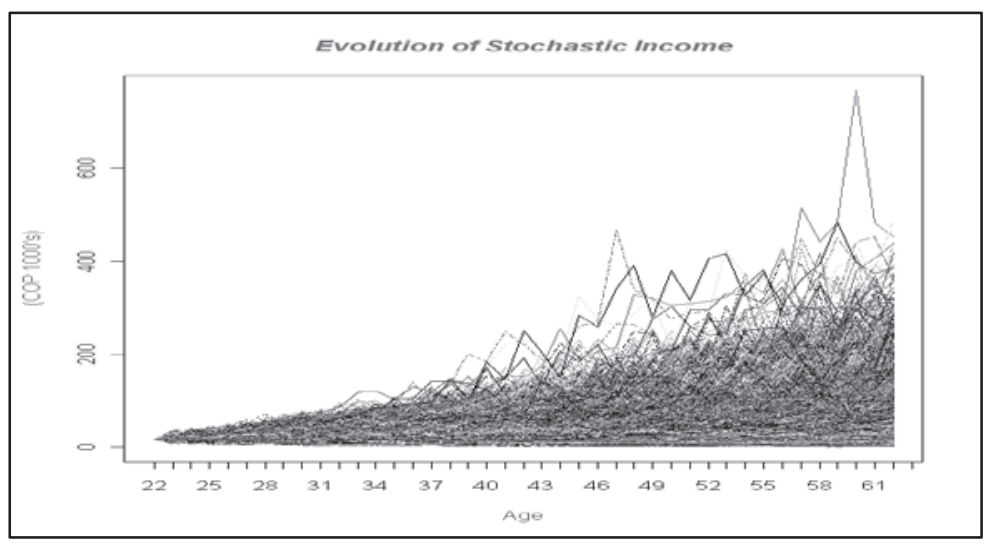

Table 7

Wage distribution at retirement in COP (1000s)

\begin{tabular}{|c|c|c|c|c|c|c|}
\hline \multicolumn{7}{|c|}{ Wage distribution at retirement in COP (1000s) } \\
\hline MINIMUM & 1 ST QU. & MEDIAN & MEAN & 3RD QU. & MAX. & STD. DEV \\
\hline 1,335 & 17,330 & 27,920 & 35,640 & 44,860 & 485,200 & $28,557.81$ \\
\hline
\end{tabular}

In the baseline case the male individual makes no contributions to a compulsory retirement pension system. Therefore, he will finance his retirement out of the savings he made during working life. In this case it is shown in Tables 8 and 9 that the results of the simulations give the following distribution for wealth at retirement, represented by a ratio between cash on hand and final wage at the age of 62 . 
Table 8

Cash on hand/final wage at retirement in COP with stochastic income (SI)

\begin{tabular}{|c|c|c|c|c|c|c|}
\hline \multicolumn{6}{|c|}{ Cash on hand/final wage at retirement in COP with stochastic income } \\
\hline MINIMUM & 1 ST QU. & MEDIAN & MEAN & 3RD QU. & MAX. & STD. DEV \\
\hline 2.14 & 10.58 & 15.58 & 20.58 & 24.49 & 426.9 & 17.04 \\
\hline
\end{tabular}

Table 9

Cash on hand/final wage at retirement in COP with non-stochastic income

\begin{tabular}{|c|c|c|c|c|c|c|}
\hline \multicolumn{6}{|c|}{ Cash on hand/final wage at retirement in COP with non-stochastic income } \\
\hline MINIMUM & 1 ST QU. & MEDIAN & MEAN & 3RD QU. & MAX. & STD. DEV \\
\hline 4.39 & 11.24 & 13.75 & 14.49 & 16.92 & 52.78 & 4.55 \\
\hline
\end{tabular}

The mean accumulation of wealth at retirement, is about 20 times final wage when there is stochastic income, and about 14 times when income is non stochastic. This result is related to the fact that when income is non stochastic, the only source of risk comes from the stochastic financial returns that the individual gets from his savings. While the individual with risky income has not only this uncertainty, but also the risk in the evolution of his wage. This cause a standard deviation of the ratio for risky income much higher than the case when income is non stochastic.

The results of the simulations also show in Figures 4, 5 and 6 how asset allocation changes across the lifecycle. In the case of stochastic labour income the individual starts to decrease his allocation to risky assets approximately after 18 years of working life while the individual with non-stochastic income starts to reduce this allocation approximately 15 years later. One of the reasons for this behavior as explained in Cocco et al. (2005) is that a male 
individual with non-stochastic income lacks a precautionary savings motive. Thus the little wealth he accumulates compared to a still large stock of human capital will oblige this investor to be $100 \%$ into stocks until a reasonable amount of savings is collected. At the same time, even when savings are accumulated an individual with non-stochastic income will not have to experience a crowding out of his financial savings, or out of the risky asset, since his stock of human capital is riskless and this makes possible for him to hold more risky assets than the male individual with risky income.

Retirement will be financed by the savings accumulated during working life. Net income in this case will be the same as wage since there are no contributions to the pension system and consumption will rise as the end of life approaches, since there is no bequest motive. The discount factor in this case in not so high so individuals appreciate later consumption. It can be seen in Figure 4 that, with different discount factors the evolution of late consumption will vary.

Figure 4

Mean consumption for different subjective discount factors in the case of no compulsory pension system and stochastic income

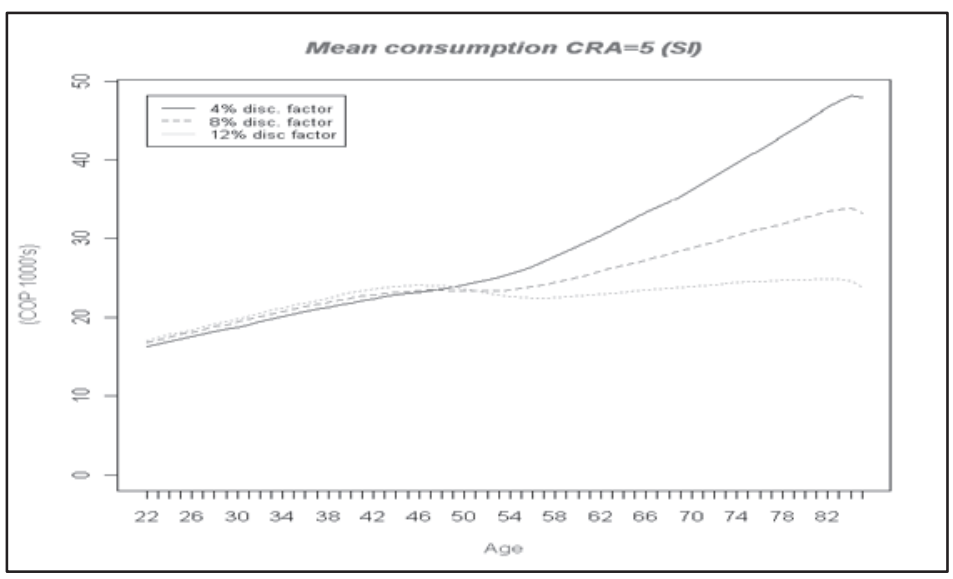


Note that in the model for this research, the formula for consumption is a percentage of total wealth that depends on a fixed set of parameters and time. In this case, can be seen in Figure 5 that since the individual with non-stochastic income doesn't have savings for the first part of his working life, and his human capital starts to deplete, his consumption will fall. With rising mean income his savings will start to grow.

\section{Figure 5}

Lifecycle paths for the case of no compulsory pension system with non-stochastic income and a CRA (Coefficient of Risk Aversion) of 5

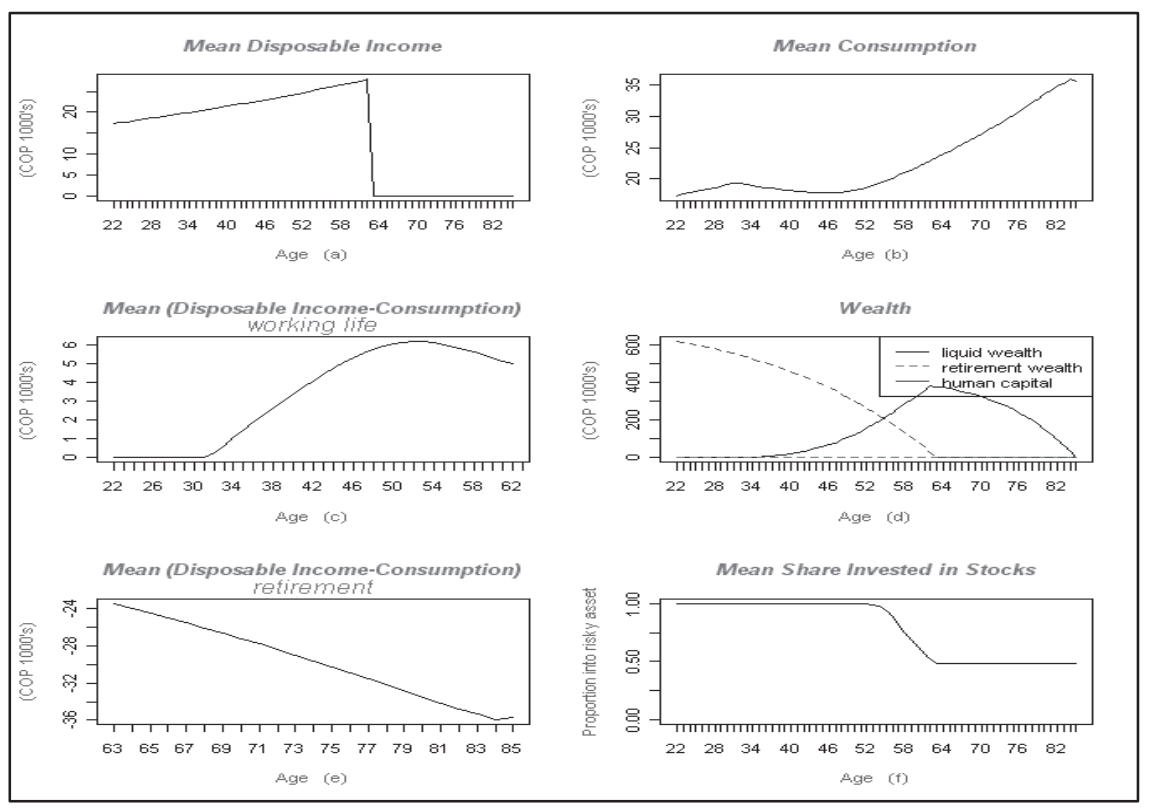




\section{Figure 6}

Lifecycle paths for the case of no compulsory pension system with stochastic income and a CRA (Coefficient of Risk Aversion) of 5

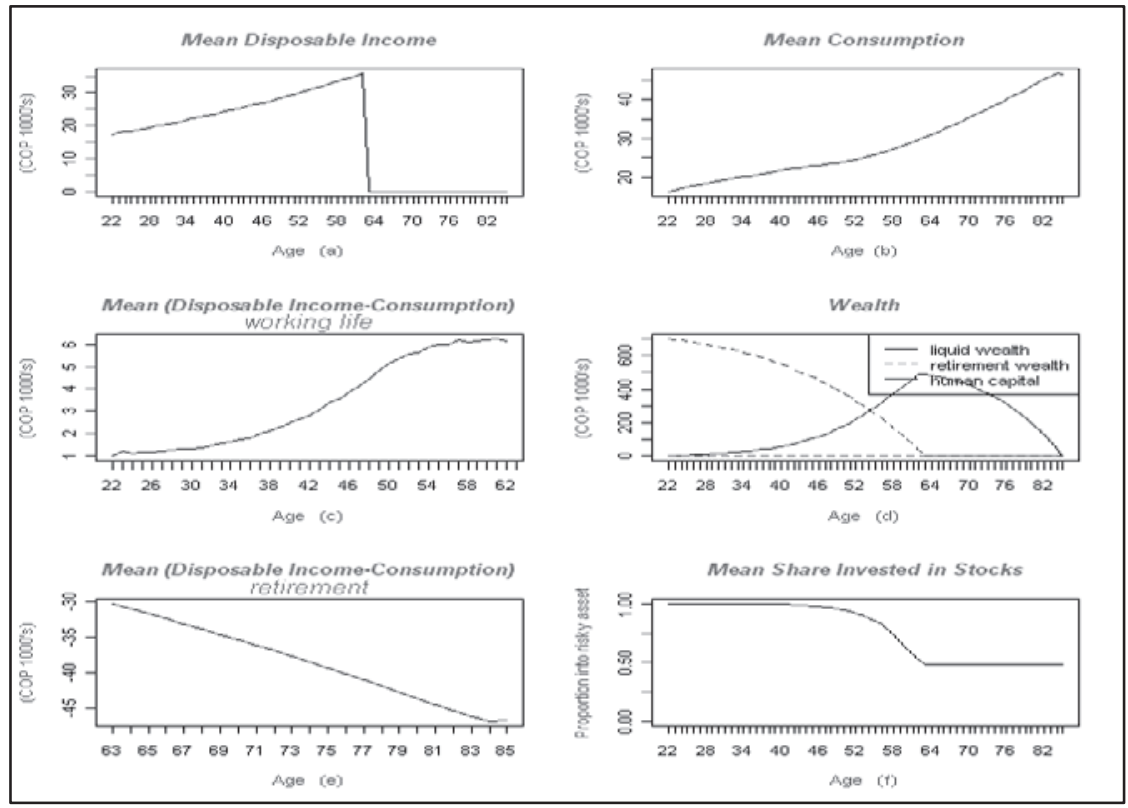

\section{a. INTRODUCING THE MULTIFUND SYSTEM}

When the compulsory system is introduced, and the male individual with risky income chooses the conservative multifund, the lifecycle paths will change in the following way:

The agent will accumulate average retirement wealth which will be composed of compulsory savings and non-compulsory savings of 18.21 times final wage; 8.49 times saved in the retirement wealth account; and 9.72 times in the liquid wealth account (Table 10). 
Table 10

Cash on hand/final wage at retirement in COP with stochastic income compulsory and non-comp savings

Cash on hand/final wage at retirement in COP with stochastic income compulsory
and non-comp savings
\begin{tabular}{|l|c|c|c|c|c|c|c|}
\hline TYPE OF WEALTH & MINIMUM & 1 ST QU. & MEDIAN & MEAN & 3RD QU. & MAX. & STD. DEV \\
\hline Retirement & 1.40 & 5.38 & 7.40 & 8.49 & 10.33 & 76.48 & 4.57 \\
\hline Liquid & 1.28 & 4.63 & 6.61 & 9.72 & 10.48 & 299.20 & 10.59 \\
\hline
\end{tabular}

In this case the average replacement ratio for the individual will be approximately $28 \%$ of the last working year average wage, and he will finance his consumption in retirement by the income that the compulsory retirement fund will provide, plus the cash on hand he accumulated during working life.

Figure 7 shows how asset allocation for liquid wealth will change with different types of multifunds.

\section{Figure 7}

Mean asset allocation for different multifunds

and no compulsory pension system with stochastic income

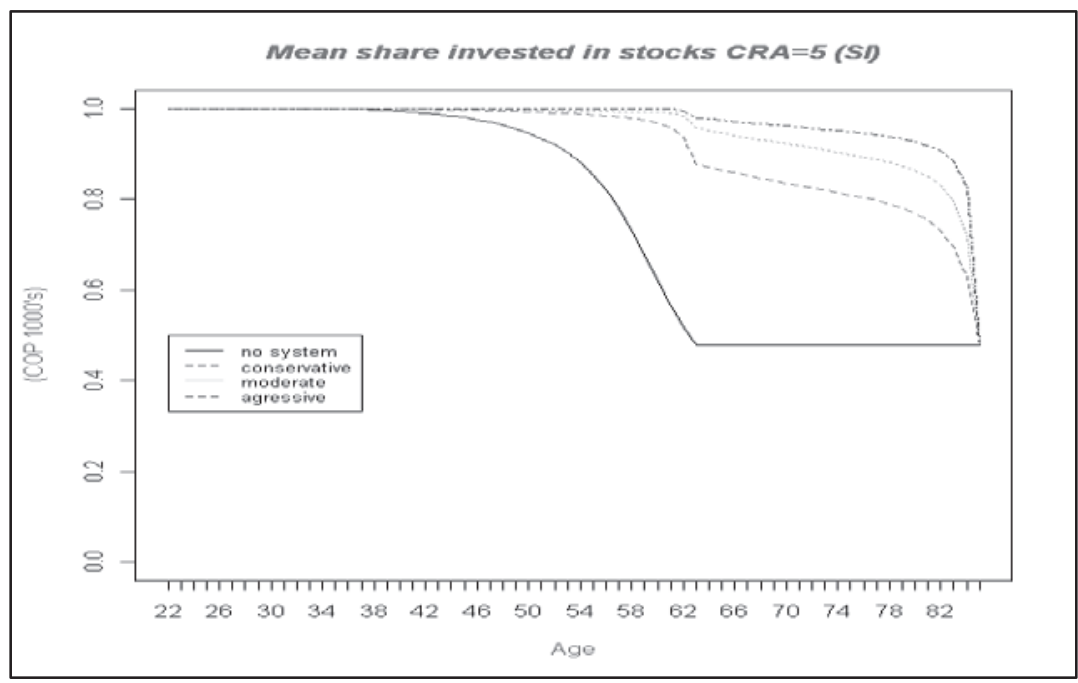


Figure 8(f) shows the asset allocation of liquid wealth. It can be seen that this allocation into the risky asset will fall around the age of 46 . In contrast to the case with no compulsory pension system this allocation will be higher for a longer time, since now the individual will consider the compulsory pension savings in retirement as riskless wealth, as in Campbell et al., (1999).

\section{Figure 8}

Lifecycle paths for the case of compulsory pension system stochastic income and conservative multifund for a CRA (Coefficient of Risk Aversion) of 5

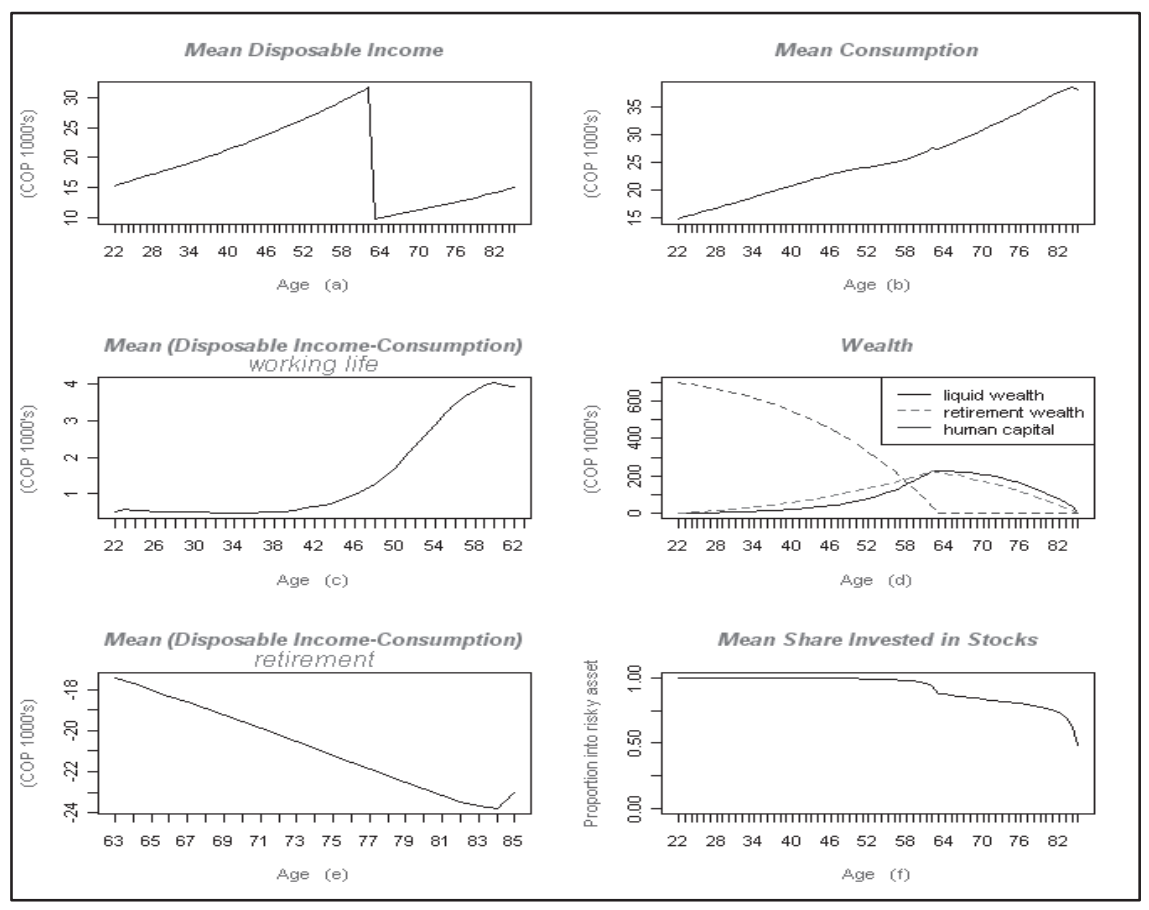




\section{B. Welfare Analysis}

Last section was dedicated to give some intuition behind asset allocation changes during the lifecycle. This section addresses the effects on welfare of different multifund choices for individuals with different risk preferences and labour characteristics through the analysis of Certain Equivalent Consumption (CEC). CEC is the monetary amount that a male individual should receive in order to get the same expected utility that he will get from consumption in the lifecycle process.

In this model CEC is the result of the following equality:

$$
C E C=\left(\frac{E\left[\sum_{t=1}^{T} \delta^{t-1} \frac{C_{t}^{1-\gamma}}{1-\gamma}\right] * 1-\gamma}{\sum_{t=1}^{T} \delta^{t-1}}\right)^{\frac{1}{1-\gamma}} .
$$

For each of the 100,000 simulations the individual will have an expected utility that will be converted to CEC, and then welfare is going to be represented by the average CEC for these simulations. In this evaluation a higher number means that the agent will prefer the alternative against another with a lower CEC.

\section{a. Non Stochastic InCOME (NSI)}

When income is non stochastic, can be seen in Table 11(a) that CEC rises when individuals with different Coefficients of Risk Aversion (CRA) choose the aggressive multifund. In the case of an individual with a risk aversion of 2 the rise in his utility from choosing the aggressive multifund compared to the conservative fund is in the 
order of $6.31 \%$, for coefficients of 5 and 8 gains are $2.13 \%$ and $1.24 \%$ respectively. In this case the results tell us that choosing the aggressive multifund enhances the ex-ante welfare of young workers.

Table 11(b) shows that choosing the aggressive multifund, gives the highest ratio between the mean $\mathrm{CEC}$ in the baseline case with no compulsory system and average CEC when the compulsory system is introduced. In this case the aggressive fund reaches between $97 \%$ and $98.5 \%$ of the welfare benchmark for all CRA's. The loss against the benchmark can be explained in Figure 9 by the fact that individuals are making suboptimal consumption choices when they are young since they are constrained and that causes a lower CEC.

\section{Table 11}

Mean CEC with non-stochastic income in COP (1000's) (a) and \% benchmark (b)

\begin{tabular}{|c|c|c|c|c|}
\hline \multicolumn{5}{|c|}{ Mean CEC with non-stochastic income (a) } \\
\hline CRA & CONSERVATIVE & MODERATE & AGGRESSIVE & NO SYSTEM \\
\hline 2 & 16,960 & 17,490 & 18,030 & 18,590 \\
\hline 5 & 17,350 & 17,560 & 17,720 & 18,410 \\
\hline 8 & 16,920 & 17,030 & 17,130 & 17,390 \\
\hline \multicolumn{5}{|c|}{$\%$ benchmark (b) } \\
\hline CRA & CONSERVATIVE & MODERATE & AGGRESSIVE & NO SYSTEM \\
\hline 2 & $91.2 \%$ & $94.1 \%$ & $97.0 \%$ & $100.0 \%$ \\
\hline 5 & $94.2 \%$ & $95.4 \%$ & $96.3 \%$ & $100.0 \%$ \\
\hline 8 & $97.3 \%$ & $97.9 \%$ & $98.5 \%$ & $100.0 \%$ \\
\hline
\end{tabular}




\section{Figure 9}

Average consumption paths for different multifunds and no compulsory system with non-stochastic income.

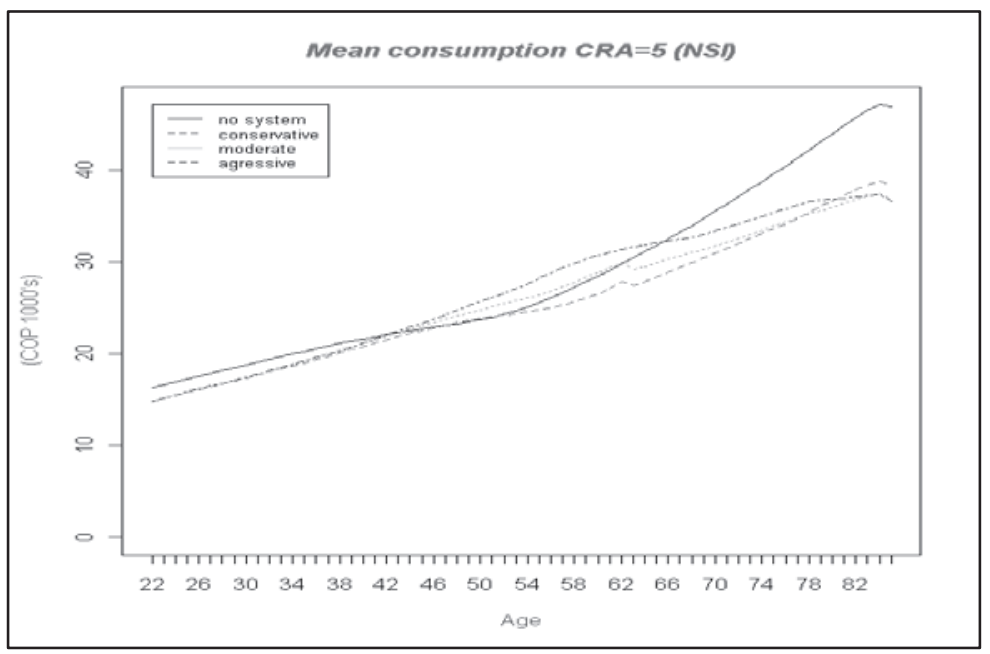

b. Stochastic InCOME (SI)

When uncertainty in labour income is introduced the results are similar, in this case we find in Table 12 that all individuals increase their utility although less pronounced that in the case with nonstochastic income. In fact for a CRA of 8 the difference is very small. One of the reasons for this finding as exposed in Campbell et al. (1999) is that under power utility, higher risk aversion implies a higher desire for smoother intertemporal consumption, since in the case of multifunds by law is not possible to lower the contribution rate then risk averse individuals will not appreciate the full potential of the higher financial returns they could earn by investing in the aggressive multifund. Another reason is argued in Pratt et al. (1987) in which they show that under power utility functions, certain individuals will be less prone to accept extra risks when there are 
already risks present. In this case, the risk of stochastic income in the future coupled with stock market risk will make individuals with high CRA to be less inclined to choose the aggressive multifund.

\section{Table 12}

Mean CEC with stochastic income in COP (1000's) (a) and $\%$ benchmark (b)

\begin{tabular}{|c|c|c|c|c|}
\hline \multicolumn{5}{|c|}{ Mean CEC with stochastic income (a) } \\
\hline CRA & CONSERVATIVE & MODERATE & AGGRESSIVE & NO SYSTEM \\
\hline 2 & 17,560 & 17,970 & 18,370 & 19,620 \\
\hline 5 & 16,780 & 16,860 & 16,900 & 18,380 \\
\hline 8 & 15,610 & 15,640 & 15,670 & 16,870 \\
\hline \multicolumn{5}{|c|}{$\%$ benchmark (b) } \\
\hline CRA & CONSERVATIVE & MODERATE & AGGRESSIVE & NO SYSTEM \\
\hline 2 & $89.5 \%$ & $91.6 \%$ & $93.6 \%$ & $100.0 \%$ \\
\hline 5 & $91.3 \%$ & $91.7 \%$ & $91.9 \%$ & $100.0 \%$ \\
\hline 8 & $92.5 \%$ & $92.7 \%$ & $92.9 \%$ & $100.0 \%$ \\
\hline
\end{tabular}

In Figure 10 it is shown how different decisions will affect the behavior of consumption and liquid wealth for the male individuals under study. We can see in Figure 10(c) that the least risk averse agent will barely save outside of the compulsory pension system. The least amount of savings comes when the male individual chooses the aggressive multifund. In all cases he will increase his consumption during working life and then he will start to reduce that consumption in the retirement stage. Under power utility this individual appreciates present consumption more than later consumption, and since the expected value of accumulated savings will be higher with the aggressive multifund, he will save some portion of this retirement income in order to maintain consumption during his last years. 
For other CRA's the behavior will be similar in the sense that the expectation of a higher retirement income through the aggressive multifund will make saving outside the compulsory pension system less necessary. However, note that a high risk averse individual will start to save sooner, so he can maintain his preferred level of consumption later in life. In all cases the patterns of saving and consumption are approximately the same and start to change when individuals reach the age of 40 or more. This comes from the fact that after 18 years of contribution savings individuals will start to see different financial results depending on the exposure to the stock market.

\section{Figure 10}

Consumption and liquid wealth comparison for different Coefficients of Risk Aversion, multifunds and in the case of no system in the presence of stochastic income.

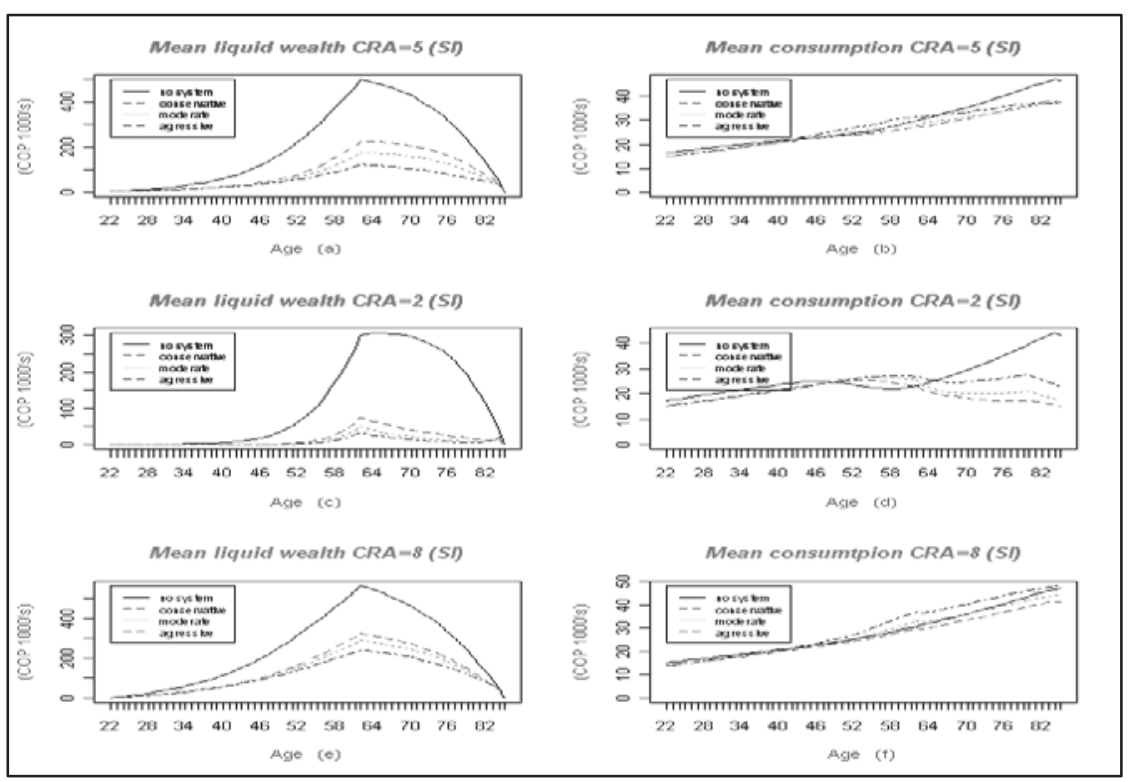




\section{Robustness checks}

a. INTRODUCING CORRELATION AND THE PROBABILITY OF A DISASTROUS INCOME SHOCK

The results from introducing a $\beta_{H}$ of 0.18 as proposed by De Jong (2008) are similar to the results discussed above, but as a robustness check inspired by Cocco et al. (2005) introducing a disastrous labour income draw which is the possibility of zero income, we get results that introduce a powerful source of background risk that may make individuals less aggressive in their decisions toward choosing a multifund with a higher allocation into risky assets.

In Table 13 it can be seen that if we introduce a $1.5 \%$ probability of an annual persistent zero income shock, then on average even the least risk averse individual of the group will see a drop in average $\mathrm{CEC}$ by choosing the aggressive multifund.

\section{Table 13}

Mean CEC with stochastic income and probability of disastrous income of $1.5 \%$ in COP (1000's) (a) and \% benchmark (b)

\begin{tabular}{|c|c|c|c|c|}
\hline \multicolumn{5}{|c|}{ Mean CEC with stochastic income and probability of disastrous } \\
\hline income of 1.5\% (a) \\
\hline 2 & 11,440 & 11,280 & 11,200 & 14,600 \\
\hline 5 & 13,350 & 13,330 & 13,100 & 15,690 \\
\hline 8 & 13,470 & 13,430 & 13,420 & 15,210 \\
\hline \multicolumn{5}{|c|}{$\%$ benchmark (b) } \\
\hline CRA & CONSERVATIVE & MODERATE & AGGRESSIVE & NO SYSTEM \\
\hline 2 & $78.4 \%$ & $77.3 \%$ & $76.7 \%$ & $100.0 \%$ \\
\hline 5 & $85.1 \%$ & $85.0 \%$ & $83.5 \%$ & $100.0 \%$ \\
\hline 8 & $88.6 \%$ & $88.3 \%$ & $88.2 \%$ & $100.0 \%$ \\
\hline
\end{tabular}


This result again may be related to the fact exposed in the case of introducing stochastic income, in the sense that a probability of a persistent annual zero income shock, could cause individuals to adopt less risky choices. In this case, this means choosing the conservative multifund for the three levels of risk aversion under study.

In Table 13(b) it can be seen that there is a big loss of welfare between the case with no system and the multifund system. It could be argued that the cause of this result is that this labour income risk constitute a potent source of background risk, and individuals will not want to assume more stock market risk. This explanation is argued in Cocco et al. (2005) but they also mention that this type of investment behavior is still challenging to explain.

\section{b. THE POINT OF VIEW OF A MIDDLE AGE INVESTOR}

Until this point, the welfare analysis has been based on the point of an investor at the start of his working life. Another variation of the analysis will be to find out which multifund can give the highest exante utility for an individual age 45 , by calculating the CEC at the age of 45 instead of the age of 22 as has been done in the previous simulations.

In Table 14 we can see that with non-stochastic income the middle age individual will increase his ex-ante utility by choosing the aggressive multifund. At the same time the magnitude of the increase in welfare is higher for each CRA. Compared to the case of the young individual, these results are in line with the findings of Campbell et al. (1999) in the sense that the older male individual can enjoy the benefits of having greater wealth in the compulsory pension fund, and as a result this wealth will allow him to enjoy higher consumption in the future (using as reference for this higher wealth the median expected value of compulsory savings at the age of retirement). 


\section{Table 14}

Mean CEC with non-stochastic income for a 45 year old individual in COP (1000's) (a) and \% benchmark (b)

\begin{tabular}{|c|c|c|c|c|}
\hline \multicolumn{5}{|c|}{ Mean CEC with non-stochastic income for a 45 year old individual (a) } \\
\hline CRA & CONSERVATIVE & MODERATE & AGGRESSIVE & NO SYSTEM \\
\hline 2 & 16,860 & 18,530 & 20,580 & 18,010 \\
\hline 5 & 18,800 & 19,720 & 20,780 & 19,370 \\
\hline 8 & 19,430 & 20,150 & 20,890 & 21,320 \\
\hline \multicolumn{5}{|c|}{$\%$ benchmark (b) } \\
\hline CRA & CONSERVATIVE & MODERATE & AGGRESSIVE & NO SYSTEM \\
\hline 2 & $93.6 \%$ & $102.9 \%$ & $114.3 \%$ & $100.0 \%$ \\
\hline 5 & $97.1 \%$ & $101.8 \%$ & $107.3 \%$ & $100.0 \%$ \\
\hline 8 & $91.1 \%$ & $94.5 \%$ & $98.0 \%$ & $100.0 \%$ \\
\hline
\end{tabular}

In the case of stochastic income it can be seen in Table 14 that there is also an increase in utility by choosing the aggressive multifund. Although the gains are smaller than in the case of non-stochastic income, but higher than in the case of the young individual with stochastic income, since in that case the gains were almost nonexistent for a CRA of 8. Now the gains from choosing the aggressive multifund against the conservative fund are around $7 \%$.

In Table 15(a) we can also see that the CEC in the aggressive and even the moderate multifund is higher than in the case without restrictions (no system) for an individual with stochastic income and a CRA of 8. This happens as well for individuals with nonstochastic income with CRA's of 2 and 5 who choose the aggressive multifund in the case of non-stochastic income (see Table 14). The reason for this results is that it is assumed that the individuals have accumulated some retirement wealth than in the case of no system they wouldn't have. Since consumption is determined by the amount of wealth accumulated, this individuals will enjoy a certain level of consumption that when is converted to CEC can be higher than the 
benchmark. The important result here is that a middle age individual will prefer the aggressive multifund regardless of his risk preferences.

\section{Table 15}

Mean CEC with stochastic income for a 45 year old individual in COP (1000's) (a) and \% benchmark (b)

\begin{tabular}{|c|c|c|c|c|}
\hline \multicolumn{5}{|c|}{ Mean CEC with stochastic income for a 45 year old individual (a) } \\
\hline CRA & CONSERVATIVE & MODERATE & AGGRESSIVE & NO SYSTEM \\
\hline 2 & 20,820 & 22,110 & 23,750 & 23,130 \\
\hline 5 & 24,300 & 25,150 & 25,810 & 25,310 \\
\hline 8 & 24,720 & 25,560 & 26,450 & 25,360 \\
\hline \multicolumn{5}{|c|}{$\%$ benchmark (b) } \\
\hline CRA & CONSERVATIVE & MODERATE & AGGRESSIVE & NO SYSTEM \\
\hline 2 & $90.0 \%$ & $95.6 \%$ & $102.7 \%$ & $100.0 \%$ \\
\hline 5 & $96.0 \%$ & $99.4 \%$ & $102.0 \%$ & $100.0 \%$ \\
\hline 8 & $97.5 \%$ & $100.8 \%$ & $104.3 \%$ & $100.0 \%$ \\
\hline
\end{tabular}

\section{c. CHANGING THE RISK PREMIUM}

Until this point all the results have been based on the assumption that the expected return on equity will be in the order of $10.39 \%$. This expected return may be too high for the future and it would be valuable to evaluate the recommendations of the model by lowering this return by half to $5.2 \%$, in order to see how sensible is the exante expected utility of a young individual to changes in the equity premium.

Table 16 shows that lowering the risk premium has a very meaningful effect in average replacement rates that can be obtained in the compulsory system. If this return is large then there is going to be a big difference in replacement rates regardless of the risk 
characteristics of income. At the same time it can be seen that when this expected return is lowered, then the replacement rates from different multifunds will be very similar.

Table 16

Avg. Replacement rate different multifunds

\begin{tabular}{|c|c|c|c|c|}
\hline \multicolumn{5}{|c|}{ Avg. Replacement rate different multifunds } \\
\hline \multirow{2}{*}{ EXP. RETURN } & INCOME & CONS & MOD & AGG \\
\hline \multirow{2}{*}{$10.39 \%$} & SI & $27,60 \%$ & $38,00 \%$ & $54,20 \%$ \\
\cline { 2 - 5 } & NSI & $31,54 \%$ & $44,20 \%$ & $63,54 \%$ \\
\hline \multirow{2}{*}{$5.20 \%$} & SI & $22,24 \%$ & $23,82 \%$ & $25,34 \%$ \\
\cline { 2 - 5 } & NSI & $25,23 \%$ & $27,05 \%$ & $29,07 \%$ \\
\hline
\end{tabular}

The effect of similar replacement rates is that individuals will have to save more outside of this compulsory system in order to smooth consumption, regardless of which multifund they choose. This is in contrast to what can be seen when the expected return is large. It is possible to compare savings and consumption behavior in figure 11 when the expected return is low, in contrast to figure 10 which show this behavior when this return is larger.

As a consequence of the behavior mentioned above the welfare expectations will change as shown in Tables 17 and 18. In the case of non-stochastic income as well as in the case of stochastic income, there are very few differences across multifunds and in the case of non-stochastic income even little differences with the benchmark case. The explanation for this result is related to the fact that in the case of stochastic income agents will have to save more than in the case of non-stochastic income as explained in sub section 5.2.2., this precautionary savings will deviate the consumption path from the optimal pattern more markedly when young than in the case of non-stochastic income therefore we shall see a lower ratio 
against the benchmark in the case of stochastic income as opposed to the case when income is non stochastic (see Figure 12).

\section{Figure 11}

Consumption and liquid wealth comparison for different CRA's, multifunds and in the case of no system in the presence of stochastic income and risk premium of $5.20 \%$

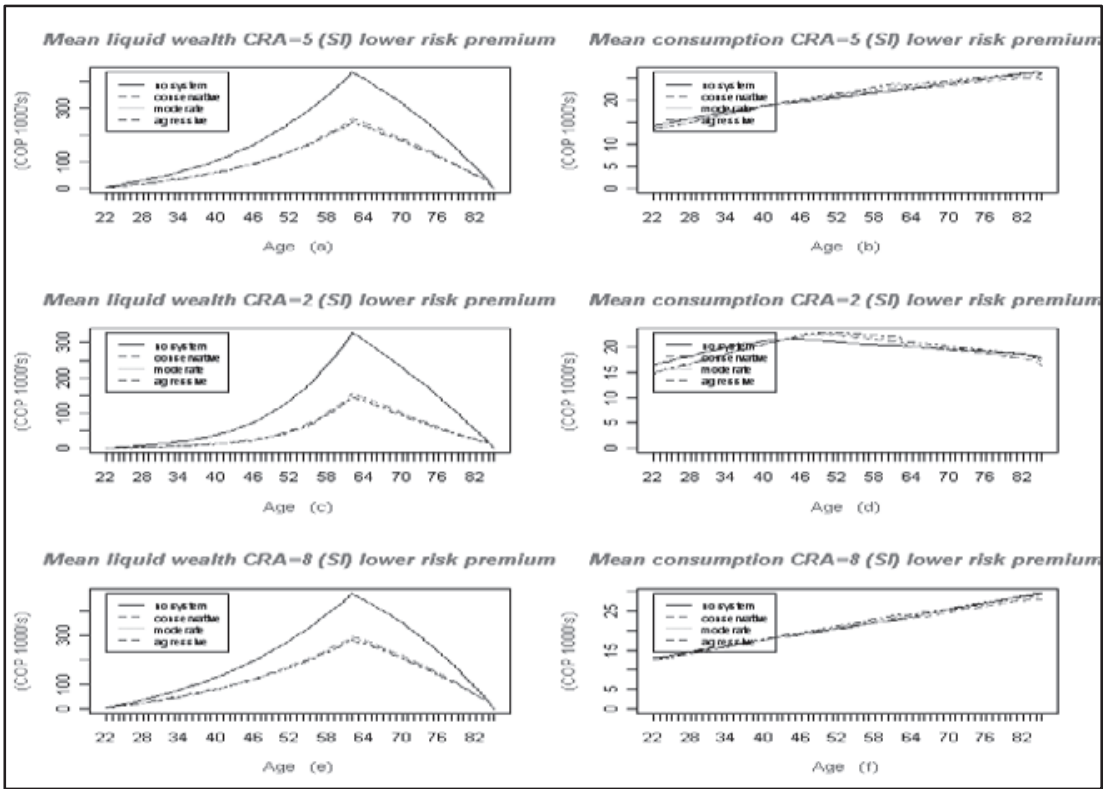




\section{Table 17}

Mean CEC with non-stochastic income and exp. Ret of 5.2\% in COP (1000's) (a) and \% benchmark (b)

\begin{tabular}{|c|c|c|c|c|}
\hline \multicolumn{5}{|c|}{ Mean CEC with non-stochastic income and exp. Ret of 5.2\% (a) } \\
\hline CRA & CONSERVATIVE & MODERATE & AGGRESSIVE & NO SYSTEM \\
\hline 2 & 16,700 & 16,750 & 16,790 & 17,120 \\
\hline 5 & 15,820 & 15,810 & 15,780 & 15,840 \\
\hline 8 & 14,380 & 14,370 & 14,360 & 14,360 \\
\hline \multicolumn{5}{|c|}{ benchmark \% (b) } \\
\hline CRA & CONSERVATIVE & MODERATE & AGGRESSIVE & NO SYSTEM \\
\hline 2 & $98 \%$ & $98 \%$ & $98 \%$ & $100 \%$ \\
\hline 5 & $100 \%$ & $100 \%$ & $100 \%$ & $100 \%$ \\
\hline 8 & $100 \%$ & $100 \%$ & $100 \%$ & $100 \%$ \\
\hline
\end{tabular}

\section{Table 18}

Mean CEC with stochastic income and exp. Ret of 5.2\% in COP (1000's) (a) and \% benchmark (b)

\begin{tabular}{|c|c|c|c|c|}
\hline \multicolumn{5}{|c|}{ Mean CEC with stochastic income and exp. Ret of 5.2\% (a) } \\
\hline CRA & CONSERVATIVE & MODERATE & AGGRESSIVE & NO SYSTEM \\
\hline 2 & 17,380 & 17,440 & 17,460 & 18,200 \\
\hline 5 & 15,750 & 15,690 & 15,690 & 16,500 \\
\hline 8 & 14,380 & 14,340 & 14,340 & 15,030 \\
\hline \multicolumn{5}{|c|}{ benchmark \% (b) } \\
\hline CRA & CONSERVATIVE & MODERATE & AGGRESSIVE & NO SYSTEM \\
\hline 2 & $95,5 \%$ & $95,8 \%$ & $95,9 \%$ & $100,0 \%$ \\
\hline 5 & $95,5 \%$ & $95,1 \%$ & $95,1 \%$ & $100,0 \%$ \\
\hline 8 & $95,7 \%$ & $95,4 \%$ & $95,4 \%$ & $100,0 \%$ \\
\hline
\end{tabular}

The results tell us that consumption will depend more on the savings obtained outside the compulsory pension system and it is going to be 
more difficult to advice individuals to which multifund can enhance better its welfare.

\section{Figure 12}

Comparison of paths of consumption in the presence of stochastic and non-stochastic income for different multifunds.

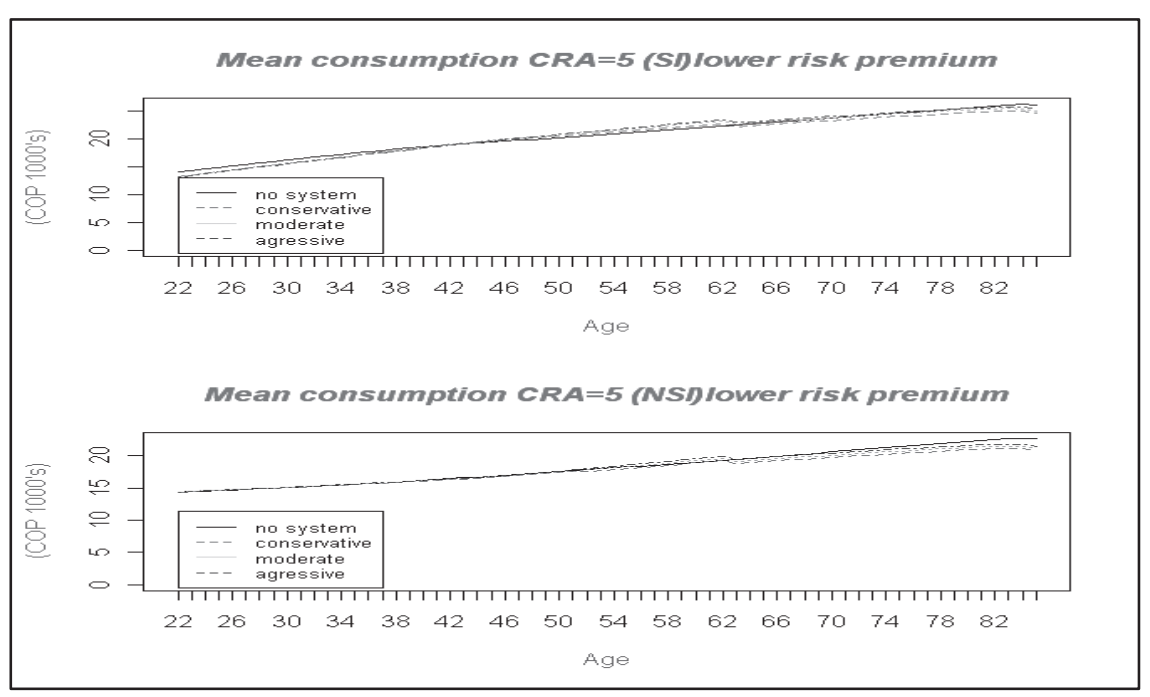

\section{Conclusions}

The main goal of this research has been to present results on the impact of welfare for individuals with different characteristics when they choose a multifund. In order to reach this goal a theoretical exercise has been carried out by simulating income profiles and financial returns within an environment that takes into account not only the wealth created within a compulsory pension system but also the decisions that these individuals may take outside of it.

It is important to point out that the results have been obtained by simulating different sets of scenarios based on specific assumptions. The main intention of this research is to point out that 
allowing for more exposure to stock returns for individual accounts in a compulsory pension system will not increase necessarily the welfare of young individuals as shown in subsections 5.C.a and 5.C.c. It is very important for the pension industry to know their clients in order to give advice that may make a difference in their lifetime well-being.

In this document the subject of wealth accumulation has been left as a secondary result and the focus has been on saving and consumption decisions across the lifecycle, with the intention to point out the importance to focus the individual's welfare not on an end of period wealth but rather as the joint consumption the individual carries out during his lifetime.

Another important thing to mention is that in this research the argument that young individuals should be more exposed to stock market returns because of the benefits of time diversification has not been used and instead this document relies almost entirely on the fact that agents shall be exposed to risky assets depending on the amount and characteristics of the human capital at their disposal.

In the results we find the importance of the characteristics of labour income on the decisions to choose a multifund, it has been found as in related literature that regardless of risk preferences when a young individual possess a riskless amount of human capital and even in the case of presence of risk in human capital then its exposure to risky assets with his financial capital should be high.

In the presence of extreme shocks to labour income then individuals regardless of their risk preferences will tend to favour financial assets with less amounts of risk, results that are in line with literature treating background risk as a way to increase the risk aversion of agents. These results may enhance the discussion in Colombia for introducing more safety pillars for retirement to people with low income or that may suffer disability since this individuals at the same time may be the ones more exposed to uncertainty in their future wages and prospects of employment. 
Finally it has been shown that when the risk premium is lowered, then the model predicts that the alternative for all individuals is to save more in order to smooth consumption across the lifecycle. It may sound common sense but as Voltaire used to say "Common sense is not so common". 


\section{Appendix 1}

The total monetary exposure into the risky asset when there is correlation between human capital returns and stock returns is given by the following equality:

$$
H C_{t} * \beta_{H}+\pi_{t}^{*} * F_{t}=\frac{\bar{\mu}-r_{f}}{\gamma * \sigma^{2}} * W_{t}
$$

Rearranging (1) in terms of $\pi_{t}^{*}$ we have:

$$
\pi_{t}^{*}=\frac{\bar{\mu}-r_{f}}{\gamma * \sigma^{2}} * \frac{W_{t}}{F_{t}}-\frac{H C_{t}}{F_{t}} * \beta_{H}
$$

Rearranging (2) we have:

$$
\pi_{t}^{*}=\frac{W_{t}}{F_{t}} *\left(\frac{\bar{\mu}-r_{f}}{\gamma * \sigma^{2}}-\frac{H C_{t}}{W_{t}} * \beta_{H}\right)
$$

Replacing (3) with $h=\frac{H C_{t}}{W_{t}}$ we have

$$
\pi_{t}^{*}=\left[\frac{\bar{\mu}-r_{f}}{\gamma * \sigma^{2}}-h * \beta_{H}\right] * \frac{1}{1-h} .
$$




\section{Appendix 2}

The total monetary exposure into the risky asset when there is correlation between human capital returns and stock returns and individuals invest part of their retirement wealth into risky assets via the compulsory pension system is given by the following equality:

$$
H C_{t} * \beta_{H}+\pi_{t}^{*} * W_{t}^{L}+W_{t}^{R} * \beta_{R}=\frac{\bar{\mu}-r_{f}}{\gamma * \sigma^{2}} * W_{t}
$$

Rearranging (1) in terms of $\pi_{t}^{*}$ we have:

$$
\pi_{t}^{*}=\frac{\bar{\mu}-r_{f}}{\gamma * \sigma^{2}} * \frac{W_{t}}{W_{t}^{L}}-\frac{H C_{t}}{W_{t}^{L}} * \beta_{H}-\frac{W_{t}^{R}}{W_{t}^{L}} * \beta_{R}
$$

Rearranging (2) we have:

$$
\pi_{t}^{*}=\left(\frac{\bar{\mu}-r_{f}}{\gamma * \sigma^{2}}-\frac{W_{t}^{R}}{W_{t}} * \beta_{R}-\frac{H C_{t}}{W_{t}} * \beta_{H}\right) * \frac{W_{t}}{W_{t}^{L}}
$$




\section{References}

Benzoni, L, P. Collin-Dufresnse and R.Goldstein (2007), "Portfolio Choice over the Life-Cycle when the Stock and Labor Markets Are Cointegrated", The Journal of Finance, Vol 62 (5), pp. 2123-2168.

Bodie, Z., R.C. MERTON and W.F. SAMUELSON (1992), "Labour supply flexibility and portfolio choice in a life cycle model", Journal of Economics: Dynamics and Control, Vol 16, pp. 427-449.

Bodie Z. (1995), "On the risk of stocks in the long run", Financial Analysts Journal.

BODIE Z. ( 2003), "Lifecycle investing in theory and practice", Financial Analysts Journal, Vol 59, No.1, pp. 24-29.

BRENNAN, M.J. and Y. XIA (2002), "Dynamic Asset Allocation under Inflation", Journal of Finance, Vol. 57(3), pp. 1201-1238.

Campbell, J.Y., J. Cocco, F. Gomes and P. Maenhout (1999), "Investing Retirement Wealth: A Life-cycle Model”, Working Paper 7029, National Bureau of Economic Research.

CAMPBell, J.Y. and I.M. ViCeiRA (1999), "Consumption and portfolio decisions when expected returns are time varying", Quarterly Journal of Economics, Vol. 114, pp. 433-495.

Campbell, J.Y., J. Cocco, F. Gomes and P. Maenhout (2001), "Stock Market Mean Reversion and the Optimal Equity Allocation of a Long-Lived Investor", European Finance Review, Vol. 5, № 3, pp. 269-292.

Cocco, J., F.J. Gomes and P.J. Maenhout (2005), "Consumption and Portfolio Choice over the Life Cycle", Review of Financial Studies, Vol. 18, pp. 491-533.

De Jong, F., P. Schotman and B. Werker (2008), "Strategic Asset Allocation, Nestpar", Panel Paper 8.

Deaton, A. (1991), "Savings and Liquidity Constraints", Econometrica, Vol. 59, pp.1221-1248. 
Heaton, J. and D.J. LuCAs (1997), "Market Frictions", Saving Behavior and Portfolio Choice.

KolJen, R.S., T.E NiJMAN and B.J. Werker (2011), “Optimal Annuity Risk Management", Review of Finance, Vol. 15, pp. 799-833.

Gourinchas, P.O. and J. PARKer (2002), "Consumption Over the Life Cycle", Econometrica, Vol. 70, pp. 47-91.

Merton, R. (1969), "Lifetime Portfolio Selection under Uncertainty: The Continuous-Time Case", Review of Economics and Statistics, Vol. 51, pp. 247-257.

Mitchell, O. and S, UtKus (2003), "Lessons from Behavioral Finance for Retirement Plan Design", Pension Research Council Working Paper. 2003-6, University of Pennsylvania.

Pratt J.W. and R. ZeCKHAUSER (1987), "Proper Risk Aversion”, Econométrica, Vol. 55, pp. 143-154.

SAMUElson, P.A. (1969), "Lifetime portfolio selection by dynamic stochastic programming", Review of Economics and Statistics, Vol. 51, pp. 239-246.

Teulings, C. and C, DE VRIES (2006), “Generational Accounting, Solidarity and Pension Losses”, De Economist, Vol. 146, pp. 63-83.

URrutia, M. (2008), "150 years of real salaries Colombia”, UCLA-CIDE Conference on Latin American Economies: History and Globalization.

VICEIRA, L. (2009), "Pension Fund Design in Developing Economies”, OECD.

Venegas A. (1996), "Precedents for pension reform in Colombia", Law Magazine, University of the North, Vol. 6, pp 1-30

WACHTER, J. 1998, "Portfolio and consumption decisions under mean-reverting returns: An exact solution for complete markets", Working paper, Harvard University. 